\title{
Americium-241 in peat bogs as a marker of the beginning of the Anthropocene: examples from Europe and North America.
}

\author{
ANDRII OLEKSANDRENKO ${ }^{1}$, PETER APPLEBY $^{2}$, \\ TOMMY NOERNBERG ${ }^{1}$ AND WILLIAM SHOTYK ${ }^{1}$ \\ ${ }^{1}$ University of Alberta \\ ${ }^{2}$ University of Liverpool \\ Presenting Author: andrii@ualberta.ca
}

Americium-241 $\left({ }^{241} \mathrm{Am}\right)$ is present in terrestrial and aquatic environment around the globe as a result of the atmospheric testing of high yield thermonuclear weapons carried out mainly in the 1950s and 1960s. Radioactive debris (including mainly ${ }^{137} \mathrm{Cs},{ }^{90} \mathrm{Sr}$, and various $\mathrm{Pu}$ isotopes) from the tests was injected high into the stratosphere where it was rapidly dispersed around the world. Over a period of months this material slowly returned to the troposphere, and from there was quickly removed by wet and dry fallout onto the earth's surface. As the matrix to detect ${ }^{241} \mathrm{Am}$ was proposed to use peat bogs - ombrotrophic peatlands in that the plants growing there receive nutrients and contaminants exclusively from the atmosphere. The purpose of this study is to determine the fidelity of ${ }^{241} \mathrm{Am}$ records in peat bog cores.

Specifically, we compare the position of the ${ }^{241} \mathrm{Am}$ concentration peak with the 1963 depth determined by ${ }^{210} \mathrm{~Pb}$ dating. We use 39 peat cores from Europe, North America, and Indonesia collected by our team during the past 30 years for studies of atmospheric deposition of trace metals, all of which had been independently dated using ${ }^{210} \mathrm{~Pb}$. We find that 18 of the cores provide an excellent agreement between the ${ }^{241} \mathrm{Am}$ and ${ }^{210} \mathrm{~Pb}$ dates, 12 were in good agreement, and 9 agreed poorly. Possible reasons for the discrepancy in the 9 cores with poor agreement are 1) the sensitivity of the gamma spectrometer for detecting ${ }^{241} \mathrm{Am}$, and 2) disruptions to the fallout records caused e.g. by disturbances to the peat bog or changes in the peat topography or hydrology. Small scale horizontal and vertical variations in bogs help explain why in a triplicate of peat cores collected from Wildseemoor in the Black Forest of Germany, excellent agreement was found in one core, good agreement in a second, and poor agreement in the third. A peat core collected from Gola di Lago, a small fen in Switzerland, showed excellent agreement; this suggests that samples from minerotrophic peatlands may also be useful to mark the start of the Anthropocene. 